\title{
Efficiency evaluation of a safety department in a construction company-A case study: A DEA approach
}

\author{
Solomon Odeyale*
}

Mechanical Engineering Department, Olabisi Onabanjo University, College of Engineering \& Environmental Science, Ogun State, Nigeria

\begin{tabular}{l}
\hline C H R O N I C L E \\
\hline Article history: \\
Received September 18, 2014 \\
Accepted 15 December 2014 \\
Available online \\
December 162014 \\
\hline Keywords: \\
Safety evaluation \\
Data envelopment analysis \\
efficiency evaluation \\
DEA \\
Construction company
\end{tabular}

\section{Introduction}

Safety involves processes designed to decrease the incidence of injury and hazard in a workplace. Safety departments in any workplace are established to implement such processes. Duties of a safety department in construction firms involve; hazard control, work site inspection, worker competency and training, incident reporting and investigation, emergency response planning etc. Safety measures incorporate prevention of workplace injuries and management of workplace hazards. It is a control measure that limits the consequences of major incidents, thus protecting the health and safety of all workers in the construction firm including employees, contractors, volunteers, trainees. Safety necessities apply to all workplaces, including construction firms. Construction companies execute many projects such as construction of buildings, bridges, assembling of infrastructures etc. In project management every project has an initiation and an expected completion date. If there is no proper safety evaluation, there may be delay in project completion because of numbers of casualties/accidents or

*Corresponding author.

E-mail addresses: solomon.odeyale@gmail.com (S. Odeyale)

(C) 2015 Growing Science Ltd. All rights reserved. doi: $10.5267 /$ j.ms 1.2014 .12 .009 
downtime due to equipment damage. Also construction activities involve the use of heavy duty machines and machineries whenever any worker is not careful with, could result to an accident that may lead to death. Thus, measuring the efficiency of a safety department is important because it gives the present safety status of the company and also determines measures to be taken for improvement. Safety efficiency varies from many areas measured by managers because the success results are in the absence of an outcome (injuries or ill health) rather than the presence. If efficiency evaluation is not carried out, the effectiveness of the health and safety management system of the firm is undermined and there is no reliable indicator on how well the safety department is doing.

Efficiency is normally measured as the ratio of output on input. To improve efficiency one has to either; increase the outputs, decrease the inputs, if both outputs and inputs increase then the rate of increase for outputs should be higher than the rate of increase for inputs, or if both outputs and inputs are decreased, then the rate of decrease for outputs has to be lower than the rate of decrease for inputs. The Data Envelopment Analysis (DEA) for efficiency measurement was first proposed by Charnes et al. (1978). The CCR is a non-parametric performance assessment methodology, which measures the relative efficiency of a set of homogeneous Decision Making Units (DMUs) such as bank branches, hospitals, construction companies, which consumes one or more inputs to produce one or more outputs. The main characteristics of DEA are that;

1. It can be applied to analyze multiple outputs and multiple inputs without pre assigned weights

2. It can be used for measuring a relative efficiency based on the observed data and

3. Decision maker preferences can be incorporated in DEA models.

Based on the literature review of DEA, there have been several researches, which involve the use of the approach for evaluation, selection, benchmarking and ranking. Weber (1996) described how DEA can be used to evaluate vendors on multiple criteria and also to identify benchmark values. Braglia and Petroni (2000) explained a multiple attribute utility theory based on the use of DEA, which helps purchasing managers to formulate viable sourcing strategies in the changing market place. Weber et al. (2000) proposed an approach for assessing the efficiency of vendors to be employed in a procurement situation using Multi-Objective Programming (MOP) and DEA. Forker and Mendez (2001) executed an analytical method for benchmarking using DEA, which helps companies identify their most efficient suppliers i.e. the most efficient suppliers with the most widely applicable Total Quality Management (TQM) programs. Gerhard (2004) proposed a model for measuring university library efficiency using DEA technique. Talluri et al. (2006) suggested a chance-constrained DEA (CCDEA) approach in the presence of multiple performance measures for selection of appropriate suppliers. Ozcan (2008) performed an assessment using DAE for health care benchmarking and performance evaluation. Bakhtair et al. (2009) carried out a performance evaluation of a maintenance department and also developed an adapted balance scorecard model using DEA. Chuen and Kuan (2010) assessed the efficiency of universities for effective allocation and utilization of educational resources, DEA model was used to evaluate the relative teaching and research efficiencies of the universities. Majid et al. (2010) introduced a new mathematical method for improving the discrimination power of DEA and to completely rank the efficient decision-making units (DMUs). Francisco et al. (2010) demonstrated a connection between DEA and a non-interactive elicitation method to estimate the weights of objectives for decision-makers in a multiple attribute approach. Wang and Chin (2010) proposed some new alternative models for DEA cross-efficiency evaluation to provide more methodological options for the decision makers (DM) to choose from. Sergey and Kweku-Muata (2011) used DEA for monitoring efficiency-based performance of productivity-driven organizations and also to design and implement a decision support system for the organizations. Zhao et al. (2011) proposed a network-DEA approach for performance measurement of a transportation network with a downtown space reservation system. Kao et al. (2011) proposed a two-stage approach of integrating independent component analysis (ICA) and DEA for efficiency measurement of a firm and also for comparing their performance with their competitors. Wang and Chin (2011) proposed a "fuzzy expected value approach" for DEA in which 
fuzzy inputs and fuzzy outputs were first weighted, respectively, and their expected values were used to measure the optimistic and pessimistic efficiencies of decision making units (DMUs) in fuzzy environments. Fallah and Najafi (2012) used DEA for the efficiency evaluation and ranking of a research institute. Hassan et al. (2012) applied the non-parametric method of DEA to analyze the efficiency of farmers, discriminate efficient farmers from inefficient ones and identify wasteful uses of energy for alfalfa production. Yongjun et al. (2012) carried out a road safety risk evaluation and target setting in 27 European Union (EU) countries using data envelopment analysis. Meng et al. (2012) proposed a non-radial DEA approach consisting of both static and dynamic environmental performance index (EPI) for measuring environmental performance. Zhenlin et al. (2012) carried out an efficiency evaluation of intelligent traffic management system in Beijing using DEA method. Ke et al. (2013) adopted the two-stage network DEA to measure and improve the efficiency of the Chinese commercial banking system. Muhittin et al. (2013) proposed a methodology called the DEA model for appreciative academic self-evaluation to allocate premium points to a group of professors and also evaluating the performance of their academic faculty. Kwok (2013) investigated the feasibility of using DEA to measure efficiency and rationalize a distribution network as an alternative approach to the conventional method of optimizing delivery routes and schedules through linear programming. Guanghui et al. (2013) performed an energy efficiency performance audit on China's transport sector from 2003 to 2009 , they did not only examine the energy efficiency performance of China's transport sector, but also maximized energy-saving potential of transport sector of China's 30 administrative regions using the data envelopment analysis approach. Soltanifar and Shahghobadi (2014) demonstrated the occurrence of rank reversal in different ranking models of DEA, certain ranking methods were surveyed in the DEA methodology by focusing on rank preservation and rank reversal. Muren and Wei (2014) utilised fuzzy DEA model to reveal the necessity of sample decision making unit (DMU) and improve the $\alpha-$ cut approach. Toloo and Ertay (2014) used DEA for vendor performance evaluation and also proposed a new cost efficiency DEA (CE-DEA) approach with price uncertainty for finding the most cost efficient unit in an automotive industry in Turkey. Juan et al. (2014) used the cross-efficiency concept in DEA to evaluate cost and resource allocation problems.

\section{Methodology}

DEA is a multi-factor productivity analysis model for measuring the relative efficiencies of a homogenous set of decision making units (DMUs). The efficiency score in the presence of multiple input and output factors is defined as:

$$
\text { Efficiency }=\frac{\text { weighted sum of output }}{\text { weighted sum of input }}
$$

As we can observe from Eq. (1), in order to maximize the magnitude of efficiency, it's either emphasis is placed on reduction of inputs to improve efficiency (in DEA analysis this is called input orientation) or increasing output to achieve efficiency (in DEA this is called output orientation). Several DEA models have been developed to use either the input or output orientation, and these models emphasize proportional reduction of excessive inputs (input slacks) or proportional increment of lacking outputs (output slacks). The initial basic frontier model was developed by Charnes et al. (1978), known as the CCR model, but now widely known as the constant returns-to-scale (CRS) model. The other basic frontier model followed CRS is the variable returns-to-scale (VRS) model.

\subsection{Decision Making Unit (DMU)}

Organizations that are subjected to evaluation in the DEA analysis are called DMUs. For instance, construction organizations, universities, group practices, and other facilities that are evaluated for performance using DEA are considered as DMUs. 
The essence of the CRS model is the "ratio of maximization" of the ratio of weighted multiple outputs to weighted multiple inputs. Any construction firm's safety department compared with others should have an efficiency score of 1 or less, with either 0 or positive weights assigned to the inputs and outputs. The calculation of DEA efficiency score is given below using mathematical notations (Cooper et al., 2007). The efficiency scores $\left(\theta_{0}\right)$ for a group of peer DMUs $(j=1 \ldots n)$ are computed for the selected outputs $\left(\mathrm{y}_{\mathrm{r} j}, \mathrm{r}=1, \ldots, \mathrm{s}\right)$ and inputs $\left(\mathrm{x}_{\mathrm{ij}}, \mathrm{i}=1, \ldots, \mathrm{m}\right)$ using the following fractional programming formula of CRS model

$$
\max \theta_{\mathrm{o}} \frac{\sum_{r=1}^{\mathrm{s}} u_{r} y_{r o}}{\sum_{i=1}^{m} v_{i} x_{i o}}
$$

subject to

$$
\frac{\sum_{r=1}^{\mathrm{s}} u_{r} y_{r j}}{\sum_{i=1}^{m} v_{i} x_{i j}} \leq 1
$$

$u_{r}, v_{i} \geq 0 \quad$ for all $\mathrm{r}$ and $\mathrm{i}$

This model can be algebraically rewritten as;

$$
\max \theta_{\mathrm{o}} \quad \sum_{r=1}^{\mathrm{s}} u_{r} y_{r o}
$$

subject to

$$
\sum_{r=1}^{\mathrm{s}} u_{r} y_{r j} \leq \sum_{i=1}^{m} v_{i} x_{i j}
$$

with further manipulations the following linear programming were obtained;

$$
\max \theta_{\mathrm{o}} \quad \sum_{r=1}^{\mathrm{s}} u_{r} y_{r o}
$$

subject to

$$
\begin{aligned}
& \sum_{r=1}^{\mathrm{s}} u_{r} y_{r j}-\sum_{i=1}^{m} v_{i} x_{i j} \leq 0 \quad j=1, \ldots . . n \\
& \sum_{i=1}^{m} v_{i} x_{i o}=1
\end{aligned}
$$

where

$$
u_{r}, v_{i} \geq 0
$$

$\theta_{o}=$ efficiency score

$\mathrm{s}=$ output

$\mathrm{m}=$ input

$r=1$ to $s$,

$i=1$ to $m$,

$y_{r j}=$ amount of output $k$ produced by DMU $o$

$x_{i j}=$ amount of input $i$ utilized by DMU $o$

$u_{r}=$ weight given to output $r$,

$v_{i}=$ weight given to input $i$. 


\subsection{Assessment of the weights and benchmark}

Eqs. (2-4) identify the relative efficiency scores of all the DMUs. Individual DMU selects input and output weights that maximize its efficiency score. Thus, a DMU is considered to be efficient if it obtains a score of 1 and a score of less than 1 implies that it is inefficient. For each and every inefficient DMU, DEA identifies a set of corresponding efficient units that can be utilized as benchmarks for improvement. To obtain the benchmarks and their weights $(\lambda)$ as well as $\sum \lambda$ leading to return to scale (RTS) assessment, a dual version of Eq. (4) is formulated as;

$$
\begin{aligned}
& \min \theta_{o} \\
& \text { subject to } \\
& \sum_{j=1}^{n} \lambda_{j} x_{i j} \leq \theta x_{i o} \quad i=1, \ldots \ldots ., m \\
& \sum_{j=1}^{n} \lambda_{j} y_{r j} \leq y_{r o} \quad r=1, \ldots \ldots ., s \\
& \lambda_{j} \geq 0 \quad j=1, \ldots ., n
\end{aligned}
$$

Eq. (5) seeks efficiency by minimizing (dual) efficiency of a focal DMU ("o") subject to two sets of inequality. The first one emphasizes that the weighted sum of inputs of the DMUs must be less than or equal to the inputs of focal DMU being evaluated. The second one similarly asserts that the weighted sum of the outputs of the non-focal DMUs should be greater than or equal to the focal DMU. The weights are the $\lambda$ values. When a DMU is efficient, the $\lambda$ values would be equal to 1 (Ozcan, 2008). For those DMUs that are inefficient, the $\lambda$ values will be expressed in their efficiency reference set (ERS) (Ozcan, 2008). DEA also helps necessary improvements required in the inefficient unit's inputs and outputs to make it efficient.

\subsubsection{Slacks}

Slacks exist only for those DMU that are inefficient. It represents the leftover portions of inefficiencies; after proportional reductions in inputs or outputs, if a DMU cannot reach the efficiency frontier (to its efficient target), slacks are required to push the DMU to the frontier (target). Fig. 1 illustrates the simple case where five different firms $\mathrm{A}, \mathrm{B}, \mathrm{C}, \mathrm{D}$ and $\mathrm{E}$ use one input $x_{1}$ to produce two output $y_{1}$ and $y_{2}$. Thus, we can plot the units in a two dimensional diagram as represented in Fig. 1. The piecewise linear boundary ACD is the locus of efficient frontier curve and therefore, A, C and D are rated fully efficient. In particular, $\mathrm{A}$ and $\mathrm{C}$ are implemented as reference points for the inefficient firm $\mathrm{B}$ (i.e. $\mathrm{A}$ and $\mathrm{C}$ form firm B's reference set) since B lies within the frontier curve, therefore it's inefficient.

In Fig. 1 efficiency is described as the proportion to which outputs can be extended radially without changing the input level. To derive the efficiency of B, we simply calculate how far B can be moved towards the frontier along the dotted line through the origin. The dotted line OB intersects the efficiency frontier at B' and therefore indicates where we have the highest level of service production, maintaining the output mix of B while keeping its respective input level. B' (which, in return, is a linear combination of the actual firm $\mathrm{A}$ and $\mathrm{C}$ ) is called the virtual peer relative to which $\mathrm{B}$ is compared. Line BB' represents the slack for $\mathrm{B}$. The same applies to firm $\mathrm{E}$; to derive the efficiency of $\mathrm{E}$ we simply calculate how far $E$ can be moved back towards the frontier along the dotted line through the origin. Line EE' represents the slack for $\mathrm{E}$. 


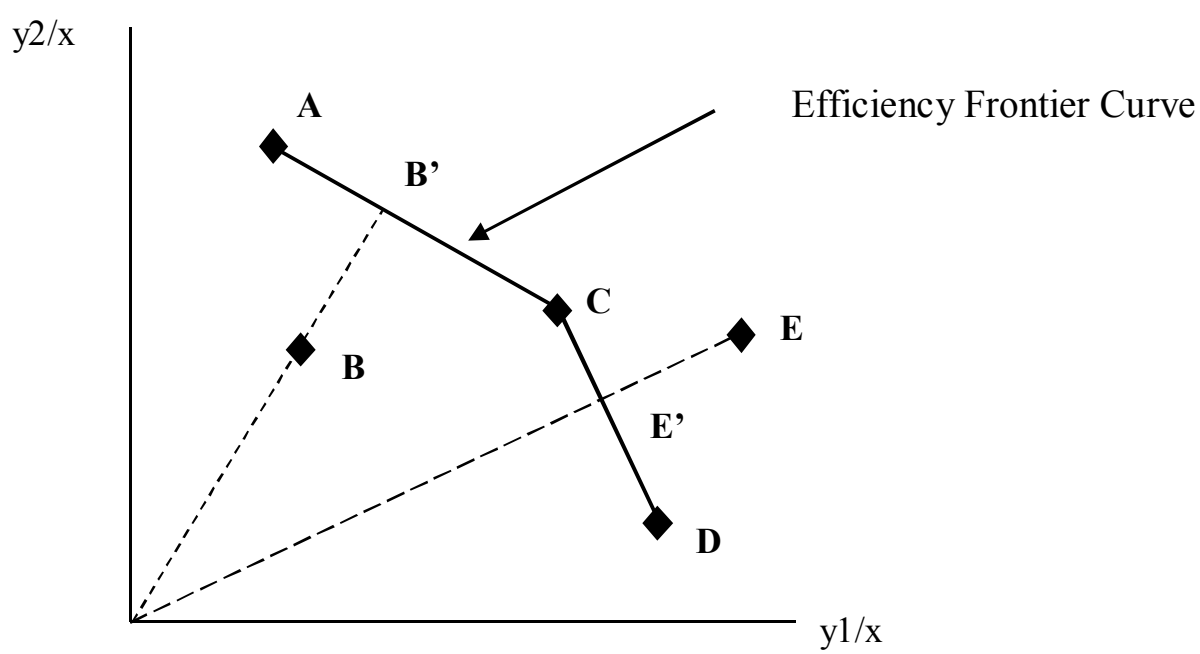

Fig. 1. Efficiency measurement using DEA

In order to calculate the slacks in DEA analysis, a second stage linear programming model is needed to be solved after the dual linear programming model (Ozcan, 2008). The second stage of the linear program is formulated for slack values as follows as (Ozcan, 2008);

$\max \sum_{i=1}^{m} s_{i}^{-}+\sum_{r=1}^{s} s_{r}^{+}$

subject to

$\sum_{j=1}^{n} \lambda_{j} x_{i j}+s_{i}^{-} \leq \theta^{*} x_{i o} \quad i=1, \ldots \ldots ., m$

$\sum_{j=1}^{n} \lambda_{j} y_{r j}-s_{r}^{+} \leq y_{r o} \quad r=1, \ldots \ldots ., s$

$\lambda_{j} \geq 0 \quad j=1, \ldots ., n$

Combining Eq. (4) and Eq. (6), we get;

$\min \theta-\varepsilon\left(\sum_{i=1}^{m} s_{i}^{-}+\sum_{r=1}^{s} s_{r}^{+}\right)$

subject to

$\sum_{j=1}^{n} \lambda_{j} x_{i j}+s_{i}^{-} \leq \theta x_{i o} \quad i=1, \ldots \ldots ., m$

$\sum_{j=1}^{n} \lambda_{j} y_{r j}-s_{r}^{+} \leq y_{r o} \quad r=1, \ldots \ldots ., s$

$\lambda_{j} \geq 0 \quad j=1, \ldots ., n$

The $\varepsilon$ in the objective function is known as the non-Archimedean, which is denoted as infinitely small, or less than any real positive number (Ozcan, 2008). The presence of $\varepsilon$ helps a minimization over efficiency score $(\theta)$ to preempt the optimization of slacks, $s_{i}{ }^{-}$and $s_{r}{ }^{+}$. Eq. (7) obtains optimal efficiency scores $\left(\theta^{*}\right)$ from Eq. (4) and calculates them. It then obtains slack values and optimizes them to achieve the efficiency frontier.

\subsection{Efficient Target Calculations for Input-Oriented CRS Model}

In input-oriented CRS models, levels of efficient targets for inputs and outputs can be measured as follows: 


$$
\begin{array}{ll}
\text { Inputs }: \hat{x}_{i o}=\theta^{*} x_{i o}-s_{i}^{-^{*}} & i=1, \ldots \ldots, m \\
\text { Outputs }: \hat{y}_{r o}=y_{r o}+s_{i}^{+^{*}} & r=1, \ldots \ldots, m
\end{array}
$$

\subsection{Evaluating a safety department}

The most important part of the efficiency evaluation is to identify the inputs and outputs for the evaluation from among a set of indicators. Note that, setting various evaluation goals leads to different input and output indicators (Fallah \& Najafi, 2012). On the other hand, the indicators in fact have the role of alerting the decision makers about the latent weak points in certain areas. For this study, the variables used for the safety evaluation are shown in the table below

\section{Table 1}

Inputs and output variable for safety evaluation

\begin{tabular}{ll}
\hline Input & output \\
\hline Workforce i.e Number of safety personnel & Number of perfect days (days/year) \\
$\begin{array}{l}\text { Safety training (hr/p) } \\
\text { Safety budget i.e amount spent of safety } \\
\text { management including salaries of safety } \\
\text { personnel }\end{array}$ & \\
\hline
\end{tabular}

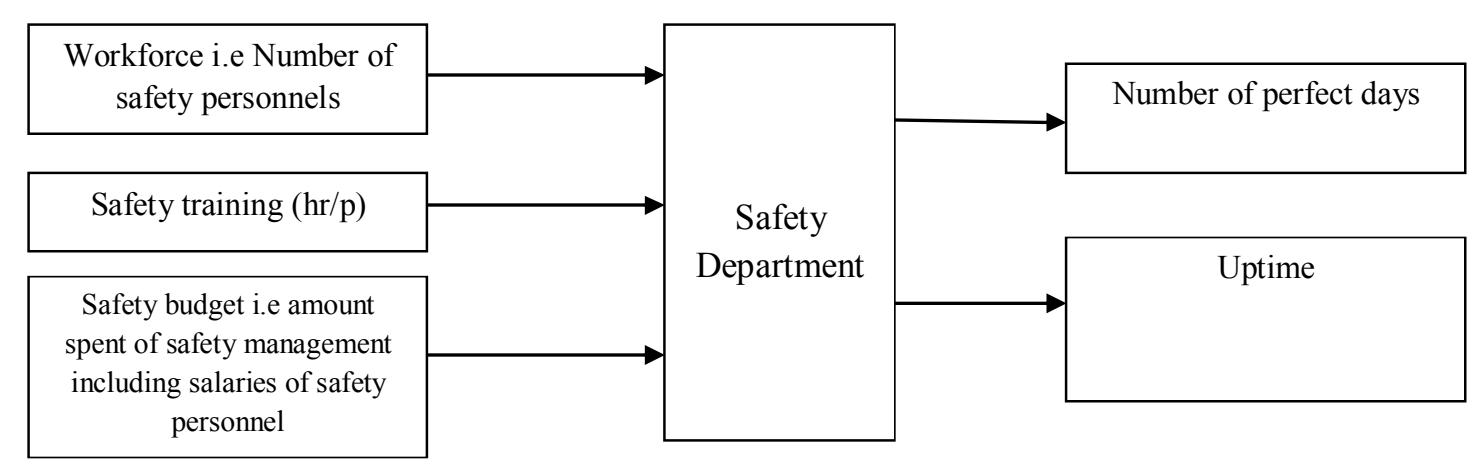

Fig. 2. Efficiency evaluation model used for this study

From the Table 1 and Fig. 2, it is seen that $m=3$ and $s=2$, therefore Eq. (4) could be written as

$\max \theta_{o}=\sum_{r=1}^{2} u_{r} y_{r o}$

subject to

$$
\begin{aligned}
& \sum_{i=1}^{3} v_{i} x_{i o}=1 \\
& \sum_{r=1}^{2} u_{r} y_{r j}-\sum_{i=1}^{3} v_{i} x_{i j} \leq 0 \quad j=1, \ldots \ldots n
\end{aligned}
$$

$u_{r}, v_{i} \geq 0$

With,

$n=$ number of safety departments under analysis

$u_{1}=$ weight of output number of perfect days (days/year)

$u_{2}=$ weight of output uptime (hrs/yr) 
$v_{l}=$ weight of input number of safety workforce

$v_{2}=$ weight of input safety training ( $\left.h r / p e r s o n\right)$

$v_{3}=$ weight of input safety budget (\$/yr)

$y_{1 o}=$ output number of perfect days (days/year) for DMU-o

$y_{2 o}=$ output number of uptime (hrs/yr) for DMU-o

$x_{1 o}=$ input number of safety workforce for DMU-o

$x_{2 o}=$ input safety training ( $\mathrm{hr} /$ person) for DMU-o

$x_{3 o}=$ input safety budget $(\$ / y r)$ for DMU-o

\subsubsection{Research Variables}

Five construction firms were considered in this study with the variable of each firm tabulated below;

Input - Workforce: Workforce is defined as the number of safety personnel present in the firm. These are the personnel that ensure that all employees adhere to the safety practices of the firm.

Table 2

Number of staffs in the safety department

\begin{tabular}{llllll}
\hline Construction firm & A & B & C & D & E \\
\hline Safety staffs & 12 & 9 & 15 & 20 & 12 \\
\hline
\end{tabular}

Input - training (hr/p): Safety trainings are all the activities carried out by safety department to enlighten workers on safety cultures. This may include teachings on the proper use of equipment to avert downtime due to casualty or equipment damages, educate employees on all workplace safety standards and the hazards they may be encounter while on a job, strict adherence and compliance to company's safety culture, correct use of PPE by workers and so on.

Table 3

Safety training (hours/person)

\begin{tabular}{llllll}
\hline Construction firm & A & B & C & D & E \\
\hline Safety training $(\mathrm{hr} / \mathrm{p})$ & 48 & 55 & 52 & 50 & 60 \\
\hline
\end{tabular}

Input - Safety budget: This is the total money spent of safety, which includes the salary of safety personnel, money used in purchase of safety kits, money used to organize safety training / programs and so on.

Table 4

Total safety budget per year

\begin{tabular}{lccccc}
\hline Construction firm & A & B & C & D & E \\
\hline Safety budget (N) & $3,800,000$ & $2,350,000$ & $4,125,000$ & $5,150,000$ & $5,000,000$ \\
\hline${ }^{*} \mathrm{~N}=$ Naira (Nigerian Currency) & & & & &
\end{tabular}

Output - Number of perfect days (days/year): Perfect day can be defined as a day when there are zero injuries or incidents, there is no harm to the environment and all of the employees return home in the same condition in which they arrived. One of the objectives of an efficiency safety management is to maximize/increase the number of perfect day.

Table 5

Number of perfect days (days/year)

\begin{tabular}{llllll}
\hline Construction firm & A & B & C & D & E \\
\hline Perfect days (days/year) & 232 & 228 & 243 & 251 & 250 \\
\hline
\end{tabular}


Output - Uptime: This is the opposite of downtime. Downtime can defined as a period whereby the firm is idle and not functioning. Downtime could be due to equipment damage or as a result of casualty. The aim of efficiency safety is to minimize downtime due to casualty and equipment damage thus maximizing uptime.

Table 6

Uptime hours (hrs/year)

\begin{tabular}{lccccc}
\hline Construction firm & A & B & C & D & E \\
\hline Uptime (hrs/year) & 2500 & 2348 & 2401 & 2480 & 2405 \\
\hline
\end{tabular}

Table 7

Input and output of the safety department in each construction firm

\begin{tabular}{|c|c|c|c|c|c|}
\hline \multirow[b]{2}{*}{$\begin{array}{l}\text { Construction } \\
\text { firm }\end{array}$} & \multicolumn{3}{|c|}{ Inputs } & \multicolumn{2}{|c|}{ Outputs } \\
\hline & $\begin{array}{c}\text { Safety staffs } \\
x_{I o} \\
\end{array}$ & $\begin{array}{l}\text { Safety Training } \\
\text { (hr/year) } x_{2 o}\end{array}$ & $\begin{array}{l}\text { Safety budget } \\
\left(\mathrm{N}^{\prime} 0000\right) x_{30}\end{array}$ & $\begin{array}{c}\text { Perfect days (hr/year) } \\
y_{1 o} \\
\end{array}$ & $\begin{array}{c}\text { Uptime } \\
\text { (hr/year) } \mathrm{y}_{2 o}\end{array}$ \\
\hline A & 12 & 48 & 380 & 232 & 2500 \\
\hline B & 9 & 55 & 235 & 228 & 2348 \\
\hline $\mathrm{C}$ & 15 & 52 & 412.5 & 243 & 2401 \\
\hline $\mathrm{D}$ & 20 & 50 & 515 & 251 & 2480 \\
\hline E & 12 & 60 & 500 & 250 & 2405 \\
\hline
\end{tabular}

\section{Results}

Table 8 shows the efficiency report of all safety departments using Eqs. (2-5), where the efficiency scores of all the five construction firms are reported. This three-input and two-output model indicates that three firms (A, B, and D) are efficient using these five dimensions (Input: safety workforce, safety training, safety budget; and Output: Perfect days and Uptime).

\section{Table 8}

Result of the CRS Input-oriented model

\begin{tabular}{|c|c|c|c|c|c|c|}
\hline \multicolumn{2}{|c|}{ Inputs } & \multicolumn{5}{|l|}{ Outputs } \\
\hline \multicolumn{2}{|c|}{ Safety workforce } & \multicolumn{5}{|l|}{ Perfect Days } \\
\hline \multicolumn{2}{|c|}{ Safety training hours } & \multicolumn{5}{|l|}{ Uptime } \\
\hline \multicolumn{7}{|c|}{ Safety budget } \\
\hline & & \multicolumn{2}{|l|}{ CRS } & & \multicolumn{2}{|c|}{ Benchmark } \\
\hline DMU No & DMU Name & Efficiency & $\sum \lambda$ & RTS & $\lambda_{1}$ & $\lambda_{2}$ \\
\hline 1 & Firm A & 1.00000 & 1.000 & Constant & 1.000 Firm A & \\
\hline 2 & Firm B & 1.00000 & 1.000 & Constant & 1.000 Firm B & \\
\hline 3 & Firm C & 0.96659 & 1.047 & Decreasing & 1.040 Firm A & 0.007 Firm D \\
\hline 4 & Firm D & 1.00000 & 1.000 & Constant & 1.000 Firm D & \\
\hline 5 & Firm E & 0.93948 & 1.088 & Decreasing & 0.494 Firm A & 0.593 Firm B \\
\hline
\end{tabular}

Firm $\mathrm{C}$ and $\mathrm{E}$ have efficiency score of less than 1 but greater than 0 , and thus they are identified as inefficient. These construction firms can improve their efficiency, or reduce their inefficiency proportionately by reducing their input. For example Firm E can improve its efficiency by reducing inputs up to $6.05 \%$ (1-0.93948). Similarly, Firm C can do the same by 3.34\% input reduction. These input reduction or output increment to improve efficiency is called slacks.

As shown in Table 9 and as earlier stated in the methodology, there are no slack for efficient firms. Slack only exists for those safety department identified as inefficient. The slack was computed using Eq. (6) and Eq. (7). Table 9 shows that Firm $\mathrm{C}$ is required to reduce its safety workforce by approximately 2 staffs, however despite the reduction in this input, it would not achieve its efficiency. No other input can be cut down, thus Firm C should also increase its uptime by 216 hours to be efficient. 
On the other hand, Firm E does not need to reduce its workforce or training hours but it needs to cut down its safety budget by N 1,424,050.63 and also increase its uptime by 224 hours to be efficient.

Table 9

Input and Output slacks for the safety department

\begin{tabular}{|c|c|c|c|c|c|c|}
\hline \multirow[b]{2}{*}{ DMU No } & \multirow[b]{2}{*}{ DMU Name } & \multicolumn{3}{|c|}{ Input Slacks } & \multicolumn{2}{|c|}{ Output Slacks } \\
\hline & & Workforce & Training & budget & Perfect Days & Uptime \\
\hline 1 & Firm A & 0.00000 & 0.00000 & 0.00000 & 0.00000 & 0.00000 \\
\hline 2 & Firm B & 0.00000 & 0.00000 & 0.00000 & 0.00000 & 0.00000 \\
\hline 3 & Firm C & 1.88249 & 0.00000 & 0.00000 & 0.00000 & 216.01537 \\
\hline 4 & Firm D & 0.00000 & 0.00000 & 0.00000 & 0.00000 & 0.00000 \\
\hline 5 & Firm E & 0.00000 & 0.00000 & 1424050.63295 & 0.00000 & 224.35127 \\
\hline
\end{tabular}

The efficiency target for each construction firm was computed using equation 8 and 9. These targets are the results of respective slack value added to the output. To compute the target values for input, the input value is multiplied with the optimal efficiency scores and then the slack amounts are deducted from this amount. For example the input target calculation for workforce (WF) input of Firm C using equation 8 is calculated as follows;

$$
\text { Input }: \hat{x}_{W F, \text { Firm } C}=\theta^{*} x_{W F, \text { Firm } \mathrm{C}}-s_{W F}^{-*}=0.96659 \times 15-1.88249=12.61640
$$

where 0.96659 comes from Table 8,15 from Table 7 , and 1.88249 from Table 9 . The efficiency target for five firms is shown in table 10. The efficient output target can be calculated using equation 9 . The perfect days (PD) and uptime (UT) for firm E is calculated as follows;

Outputs $: \hat{y}_{P D, \text { Firm E }}=y_{P D, \text { Firm E }}+s_{P D}^{+^{*}}=250+0=250 \quad \hat{y}_{U T, \text { Firm E }}=y_{U T, \text { Firm E }}+s_{U T}^{+*}=2405+224.35127=2629.35127$

Table 10

Input and output efficient targets for construction firm

\begin{tabular}{llccccc}
\hline & & \multicolumn{3}{c}{ Efficiency target Input } & \multicolumn{2}{c}{ Efficiency Target Output } \\
DMU No & DMU Name & Workforce & Training & budget & Perfect Days & Uptime \\
\hline 1 & Firm A & 12.00000 & 48.00000 & 3800000.00000 & 232.00000 & 2500.00000 \\
2 & Firm B & 9.00000 & 55.00000 & 2350000.00000 & 228.00000 & 2348.00000 \\
3 & Firm C & 12.61640 & 50.26281 & 3987194.01947 & 243.00000 & 2617.01537 \\
4 & Firm D & 20.00000 & 50.00000 & 5150000.00000 & 251.00000 & 2480.00000 \\
5 & Firm E & 11.27373 & 56.36867 & 3273338.60756 & 250.00000 & 2629.35127 \\
\hline
\end{tabular}

In Table 8 , there are two columns $\sum \lambda$ and RTS. This are used to create benchmarks as explained earlier in the methodology. Table 11, is taken from portions of the results on Table 8 . Here the construction firms whose safety departments are not efficient can observe the benchmark firms that they need to catch up with.

Table 11

Benchmarks for construction firm

\begin{tabular}{lccc}
\hline & CRS Efficiency & \multicolumn{2}{c}{ Benchmark } \\
DMU Name & & $\lambda_{1}$ & $\lambda_{2}$ \\
\hline Firm A & 1.00000 & 1.000 Firm A & \\
Firm B & 1.00000 & 1.000 Firm B & \\
Firm C & 0.96659 & 1.040 Firm A & 0.007 Firm D \\
Firm D & 1.00000 & 1.000 Firm D & \\
Firm E & 0.93948 & 0.494 Firm A & 0.593 Firm B \\
\hline
\end{tabular}

It is seen that efficient firms consider themselves to be their own benchmark. However, for the inefficient firms, their benchmarks are one or many of the efficient firms. For instance, the benchmark for Firm E is Firm A and Firm B. This means that to become efficient, Firm E must use a combination 
from both Firm A and Firm B to become efficient. The weights $\lambda_{1}$ and $\lambda_{2}$ obtained from equation 5 indicates how much of the combination an inefficient firm needs to be efficient, as shown in Table 12.

Table 12

Benchmark for Firm E

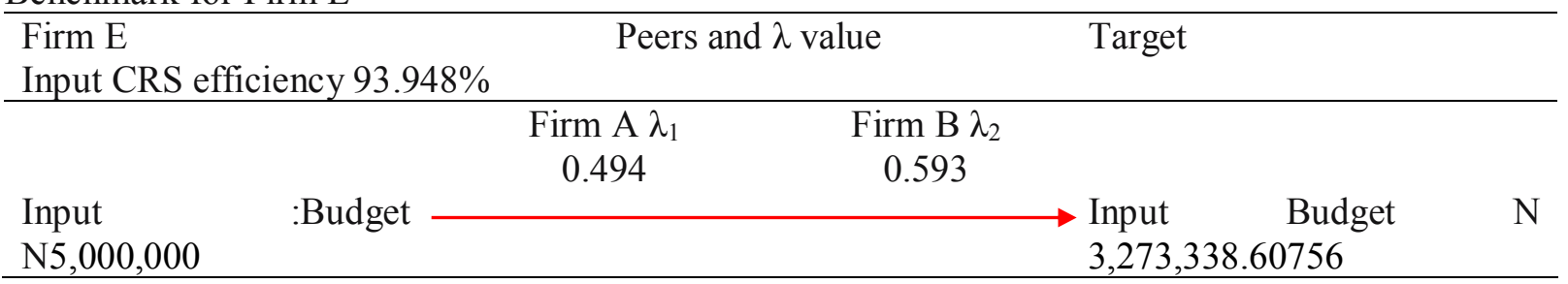

\section{Conclusion}

In this paper, DEA method has been used to evaluate the efficiency of safety departments of five different construction companies. The efficiencies of the departments were evaluated using five dimensions (Input: safety workforce, safety training, safety budget; and Output: Perfect days and Uptime). It was found that the safety department of firm A, B and D were efficient, but Firm C and Firm E can improve its efficiency by reducing inputs up to $3.34 \%$ and $6.05 \%$ respectively. As indicated by the result, there is no need to alter the safety training hour of all the five construction firms. As discussed earlier, it is very important for all construction firms to evaluate their safety department because an efficient safety department helps in the prevention of workplace injuries and management of workplace hazards, including control measures to reduce the consequences of major incidents, to ensure the health and safety of all employees. Also, construction firms execute several projects such as construction of buildings, bridges etc. and assembling of infrastructures. In project management every projects has an initiation and an expected completion date. If there is no proper safety evaluation, there could be delay in project completion date due to number of casualties/accidents and downtime due to equipment damage.

\section{References}

Bakhtiar A., Purwanggono B., \& Metasari N. (2009). Maintenance function's performance evaluation using adapted balanced scorecard model. World Academy of Science, Engineering \& Technology 58.

Braglia M., \& Petroni A. (2000). A quality assurance-oriented methodology for handling trade-offs in supplier selection. International Journal of Physical Distribution \& Logistics Management, 30(2), 96-111.

Charnes A., Cooper W., \& Rhodes E. (1978). Measuring the efficiency of decision making units. European Journal of Operational Research, 2, 429-444.

Chuen, T. K., \& Kuan, Y. W. (2010). Efficiency assessment of universities through data envelopment analysis. Procedia Computer Science, 3, 499-506.

Cooper, W. W., Seiford, L. M., \& Tone, K. (2007). Data envelopment analysis: A comprehensive text with models, applications, references and DEA-solver software, New York, Springer.

Fallah, M., \& Najafi, S. E. (2012). Efficiency evaluation and ranking of the research center at the ministry of energy: a data envelopment analysis approach. International Journal Research in Industrial Engineering, 1(1), 10- 18.

Forker L. B., \& Mendez, D. (2001). An analytical method for benchmarking best peer suppliers. International Journal of Operations \& Production Management, 21(1/2), 195-209.

Francisco, J. A., Ines, H., \& Laura, R. (2010). A modified DEA model to estimate the importance of objectives with an application to agricultural economics. Omega, 38(5), 371-382.

Gerhard R. (2004). Measuring university library efficiency using data envelopment analysis. Libri. International Journal of Libraries and Information Services, 54, 136-146. 
Guanghui, Z., William, C., \& Yixiang, Z. (2013). Measuring energy efficiency performance of China's transport sector: A data envelopment analysis approach. Expert Systems with Applications, 41(2), 709-722.

Hassan, G. M., Asadollah, A., Alireza, K., \& Ali, M. (2012). Optimization of energy required for alfalfa production using data envelopment analysis approach. Energy for Sustainable Development, 16(2), 242-248.

Juan, D., Wade D. C., Liang, L., \& Joe, Z. (2014). Fixed cost and resource allocation based on DEA cross-efficiency. European Journal of Operational Research, 235(1), 206-214.

Ke, W., Wei, H., Jie, W., \& Ying-Nan L. (2013). Efficiency measures of the Chinese commercial banking system using an additive two-stage DEA. Omega, 44, 5-20.

Kwok, H. L., (2013). Measuring distribution efficiency of a retail network through data envelopment analysis. International Journal of Production Economics, 146(2), 598-611.

Kao, L. J., Lu, C. J., \& Chiu, C. C. (2011). Efficiency measurement using independent component analysis and data envelopment analysis. European Journal of Operational Research, 210(2), 310317.

Majid, Z.A., Adli, M., \& Ali, E. (2010). Ranking efficient decision-making units in data envelopment analysis using fuzzy concept. Computers and Industrial Engineering, 59(4), 712-719.

Meng, F. Y., Fan, L. W., Zhou, P., \& Zhou, D.Q. (2012). Measuring environmental performance in China's industrial sectors with non-radial DEA. Mathematical and Computer Modeling, 58(5), 1047-1056.

Muhittin, O., Amar, O., Jean-Louis, M.,\& Ossama, K. (2013). The appreciative democratic voice of DEA: A case of faculty academic performance evaluation. Socio-Economic Planning Sciences, 48(1), 20-28.

Muren, Z. B., \& Wei, C. (2014). Generalized fuzzy data envelopment analysis methods. Applied Soft Computing, 19, 215-225

Ozcan Y.A. (2008). Health care benchmarking and performance evaluation, an assessment using data envelopment analysis (DEA). XXVI, Springer ISBN: 978-0-387-75447-5.

Sergey, S., \& Kweku-Muata, O. (2011). Using Data Envelopment Analysis (DEA) for monitoring efficiency-based performance of productivity-driven organizations: Design and implementation of a decision support system. Omega, 41(1), 131-142.

Soltanifar, M., \& Shahghobadi, S. (2014). Survey on rank preservation and rank reversal in data envelopment analysis. Knowledge-Based Systems, 60, 10-19.

Talluri S., Narasimhan R., \& Nair A. (2006). Vendor performance with supply risk: a chanceconstrained DEA approach, International Journal of Production Economics, 100(2), 212-222.

Toloo, M., \& Ertay, T. (2014). The most cost efficient automotive vendor with price uncertainty: A new DEA approach. Measurement, 52, 135-144.

Weber C. A. (1996). A data envelopment analysis approach to measuring vendor performance. Supply Chain Management, 1(1), 28-39.

Weber C. A., Current J., \& Desai A. (2000). An optimization approach to determining the number of vendors to employ. Supply Chain Management: An International Journal, 5(2), 90-98.

Wang, Y. M., \& Chin, K. S. (2010). Some alternative models for DEA cross-efficiency evaluation. International Journal of Production Economics, 128(1), 332-338.

Wang, Y. M., \& Chin, K. S. (2011). Fuzzy data envelopment analysis: A fuzzy expected value approach. Expert Systems with Applications, 38(9), 11678-11685.

Yongjun, S., Elke, H., Tom, B., Geert, W., \& Koen, V. (2012). Road safety risk evaluation and target setting using data envelopment analysis and its extensions. Accident Analysis \& Prevention, 48,430-441.

Zhao, Y., Triantis, K., Murray-Tuite, P., \& Edara, P. (2011). Performance measurement of a transportation network with a downtown space reservation system: A network-DEA approach. Transportation Research Part E: Logistics and Transportation Review, 47(6), 1140-1159.

Zhenlin, W., Peng, Z., \& Shulin A. (2012). Efficiency Evaluation of Beijing Intelligent Traffic Management System Based on super-DEA 2012. Journal of Transportation Systems Engineering and Information Technology, 12(3), 19-23. 